METALLURGY AND FOUNDRY ENGINEERING - Vol. 34, 2008, No. 1

Piotr Skubisz**, Jan Sińczak*, Paweł Chyła***

\title{
REDUCTION OF DIE LOADING BY DIVIDED FLOW PATTERN IN THE FINISHER DIE WEB AREA
}

\section{INTRODUCTION}

Flanges are very common among shapes of axi-symmetrical forged parts. Forging technologies of these parts do not particularly differ from those of other axi-symmetrical parts, however, relatively thin sections, high ribs, thin walls in combination with high strength requirements and dimensional accuracy qualify these parts in a group of complex forgings $[1,2]$. For economical reasons, efforts aimed at forging flanges directly from continuously cast billets have been made. However, large amount of deformation, high level of stresses and inconvenient metal flow pattern are reasons for the use of multi-stage open-die forging processes in manufacturing such parts [3]. Thus, a typical forging sequence in industrial practice consists of blocker and finisher forging stages, sometimes preceded by upsetting.

In the case of three-stage process the first operation is upsetting of the billet, to increase its cross-section and to provide preliminary work resulting in higher degree of deformation and higher strength of a final part. The upset-forged material is then formed in finisher-only die impression.

Most often, especially, if the flange diameter is significant, forging in finisher die is preceded by blocker operation. Additional operation of blocker forging usually increases the time of production cycle, simultaneously, reducing level of stresses in dies and increasing the tool life, which balances the total manufacturing costs. Furthermore, the blocker reduces forging load in finisher die, allowing for low capacity equipment. Last but not least, the blocker reduces the displacement of the metal in finisher impression, preventing from excessive tool wear. Not only is the blocker impression advisable for increasing tool life and reducing energy parameters, but quite often, it is necessary to prevent from flow defects formation [4].

* Ph.D., D.Sc., **Ph.D., ***M.Sc.: Faculty of Metals Engineering and Computer Sciences for Industry, AGH - University of Science and Technology, Kraków, Poland; pskubisz@metal.agh.edu.p1 
These days, in industrial practice forging of shapes similar to the analysed flange (Fig. 1) is carried out in a two-stage forging process, including upsetting and finisher. The tendency is to use cheaper forging stock, as-cast if possible. Preliminary work is to provide higher final properties and breakdown of cast structure and initial displacement of metal to fill out the impression more readily.

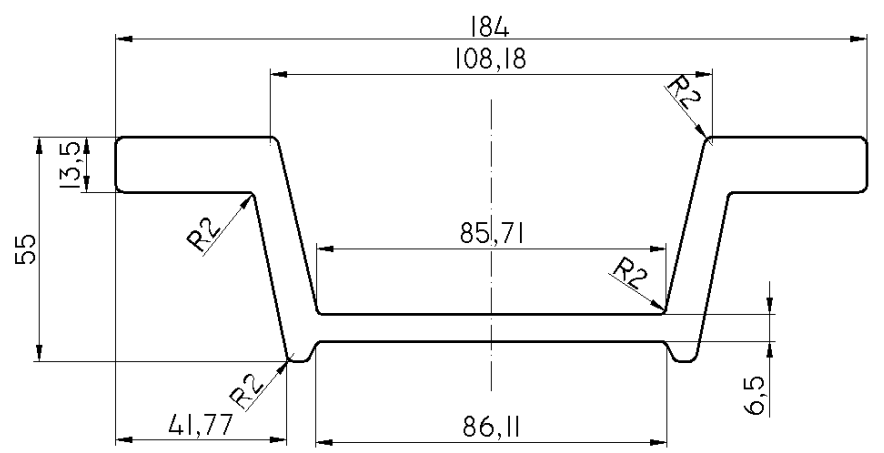

Fig. 1. Shape and dimensions of the analysed flange

However, even if flattened, the cylindrical billet very often causes unfavourable metal flow pattern and high levels of stresses, leading to damages of tools. Such problems are very common for hollow parts, where efforts are made to reduce the thickness of the web for material savings. During forming of a web, the billet is punched and the metal pushed out from the axis is forced through the thin profile into flash area. The outward metal flow in the region of the web exerts high pressure on the tools in the axis of the part, where dead zone of sort is formed. This is especially dangerous in die corners or other geometry features which provide stress concentrators.

Quite similar situations are observed in closed dies in net-forging processes, for example, in close-tolerances forging of gears. To eliminate or to reduce the dead zone with excessive hydrostatic stresses so called divided flow method is often used. One of the concepts of divided flow method boils down to utilization of hollow forging stock. In results, two directions of metal flow are provided and instead of being entrapped, the metal is allowed to flow both in inward and outward directions [5].

The idea of the work is to produce similar flow pattern in finisher die. Hence, the assumption of the new design was the profile of the web tapering towards the axis of the forging. This profile results from conical head surface of the boss in the upper die and conical bottom of the lower die, which should allow easier displacement of the material. Displacement of excessive volume of workpiece in blocker operation will produce some space for the metal to fill in in the subsequent finisher operation. Although the total amount of plastic deformation work involved will be higher, lower stresses in tools are expected.

\section{PHYSICAL MODELLING}

In order to investigate the metal flow during forging of the analysed flange (Fig. 1), physical modelling was performed. For physical simulation of the hot forging process plas- 
ticene, representing the rheology of ideal-plastic body, was used. To investigate the flow lines pattern, the billet of plasticene was cut into two halves, and rectangular grid was engraved throughout the cross-section. The experiment was carried out on low capacity laboratory hydraulic press. The analysis assumed comparison of conventional technology with two-stage concept including blocker impression.

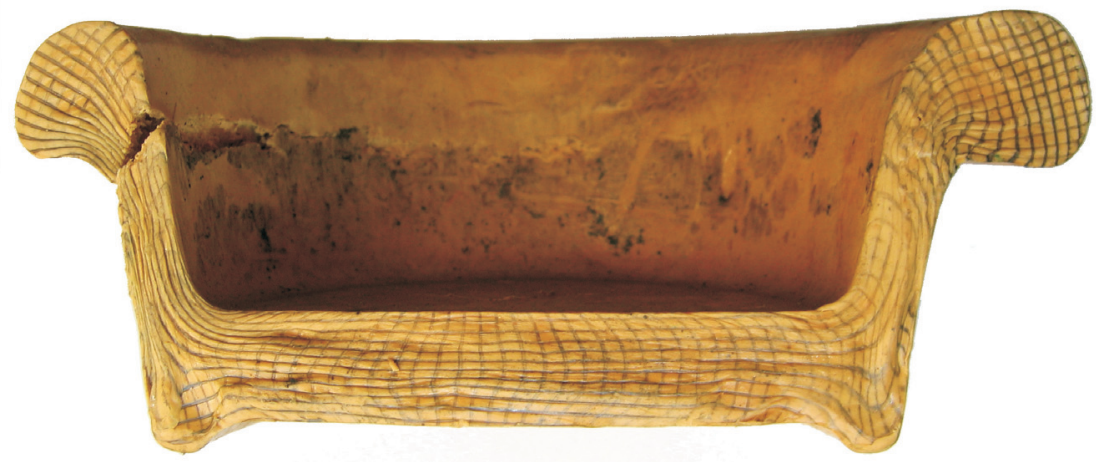

Fig. 2. Physical modelling of a conventional two-stage forging process

a)

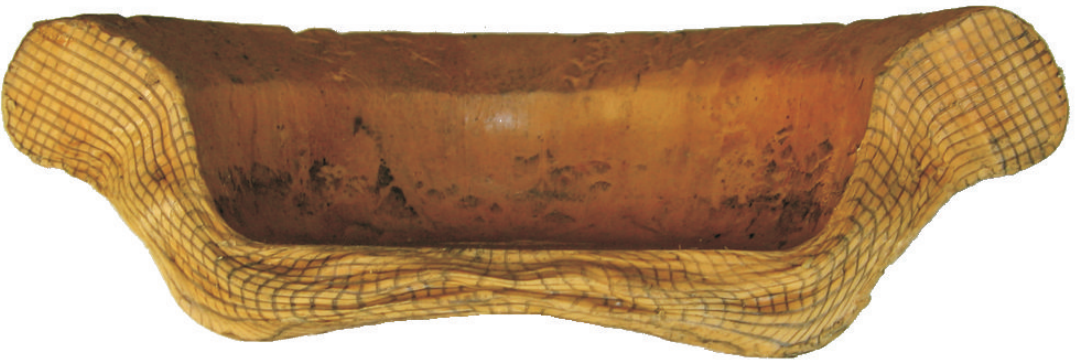

b)

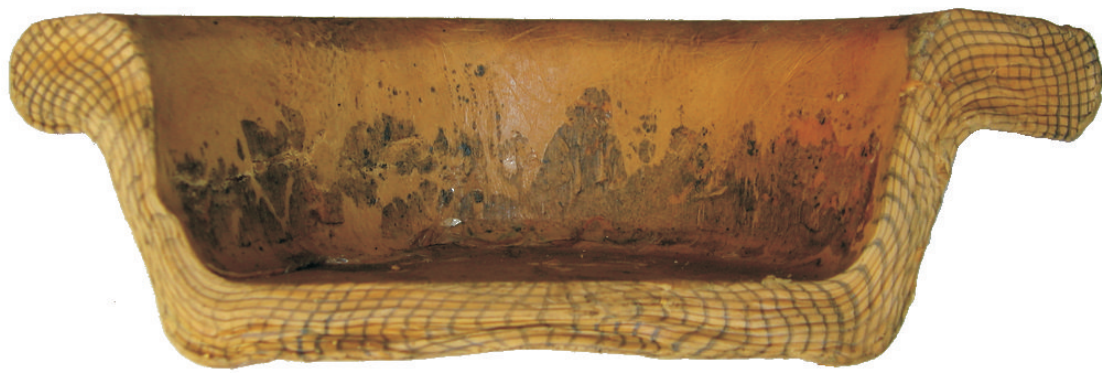

Fig. 3. Physical modelling of a three-stage forging process: a) blocker; b) finisher

The results of the physical modelling for two-stage forging are shown in Figure 2, and for the proposed three-stage process - Figure 3. As shown in Figure 2, already the physical modelling indicated high compressive stresses in the axis of the forging, which can be 
easily noticed in the thickness of the web. Also defects in the transition area from thin wall to outer flange area suggest metal flow resistance. In result, incomplete deformation of the part, producing thick web and outer walls, was obtained. Introduction of a blocker impression brought significant increase in height reduction, as can be concluded from the thickness of the web in Figure 3.

\section{NUMERICAL MODELLING}

Parallel to physical modelling, computer simulations of the forging process were performed. The aim of the simulations was analysis of obtained distribution of strain and stresses and for three selected variants of the forging process. Similarly, three technologies were investigated, however, two of them involved conventional attitude with two values of height/diameter ratio: the first one - forging without upsetting, directly from cylindrical billet of height/diameter ratio 2, and the second - with upsetting to obtain diameter as large as (close to the diameter of a finished forging). The third case included additional operation of forging the above described blocker.

The computer simulations were carried out with a use of commercial code QForm3D, based on the finite element method and rigid-viscoplastic model of body. For better visualization of results, despite axi-symmetrical shape of the part concerned, for tool stress analysis three-dimensional state of strain was assumed. The material assumed for calculations was steel X10CrMoVNb9-1, commonly used for the manufacture of high-strength pipes and flanges $[6,7]$. Boundary conditions and forging equipment kinematics, including lubricant (friction factor 0,4) and a mechanical press (40 strokes/min, stroke height $350 \mathrm{~mm}$ ), were derived from industrial practice and put in to the equipment database.

\subsection{The metal flow analysis}

The results of numerical simulations exhibit consistency with physical modelling. In both cases two-stage forging with a use of cylindrical billet unfavourable flow lines profile was observed, similar to that in plasticene. The use of undeformed billet of high slenderness resulted in formation of a lap, and flow-through defect in the corner area (Fig. 4a). Also upset-forged billet gave turbulent shape of flow lines (Fig. 4b) resulting in inclination to flow-through occurrence. Introduction of blocker impression resulted in satisfactory grain flow pattern, characterized by smooth under-surface lines profile, conforming to the contour of a part (Fig. 4c), where in the both of conventional solutions flow through defects or laps were detected.

The principle of divided flow can be observed on the basis of velocity vector observation in consecutive stages of forging. In conventional one or two-stage forging the metal is pushed out outwards from the axis of the part. With a surplus of the material or inevitable volume fluctuations in the aftermath of cutting inaccuracy, the whole impression is filled up, while the stroke is still not completed. The vectors of metal displacement are then directed toward the flash (Figs $5 \mathrm{a}$ and $5 \mathrm{~b}$ ). This favours dead zone occurrence in the centre of the part and corners or cavities in which the metal is entrapped. 
a)

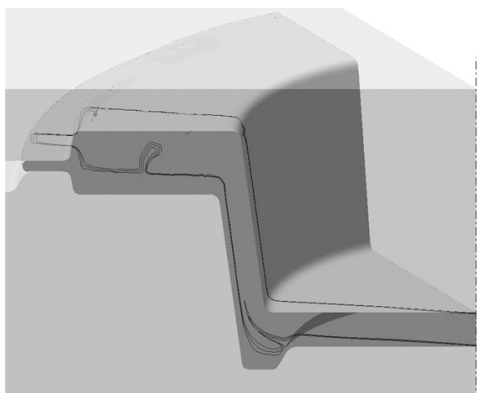

b)

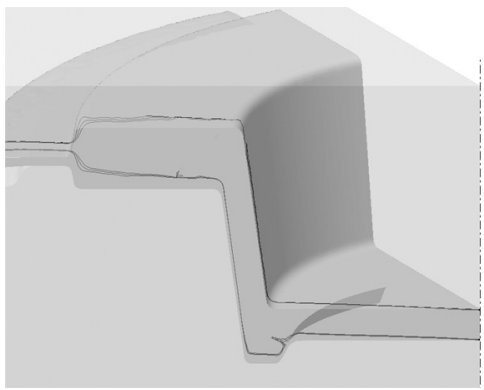

c)

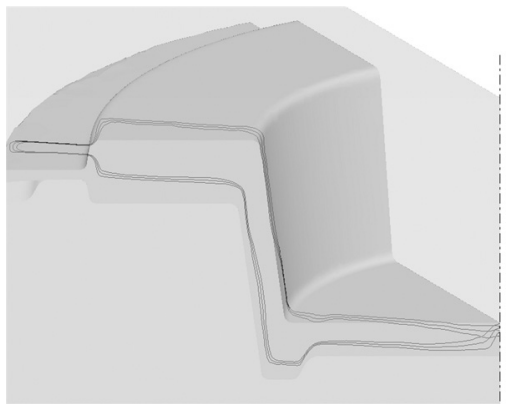

Fig. 4. Undersurface flow lines profile for different variants of forging technology: a) finisher only; b) two-stage forging; c) three-stage forging process

a)

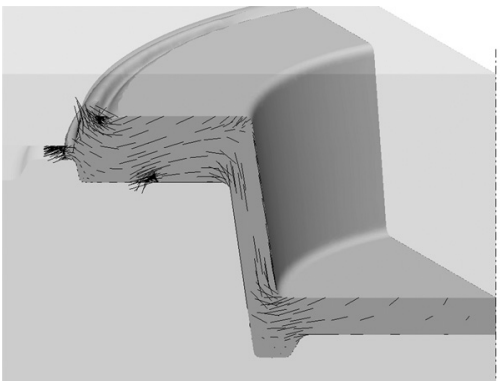

b)

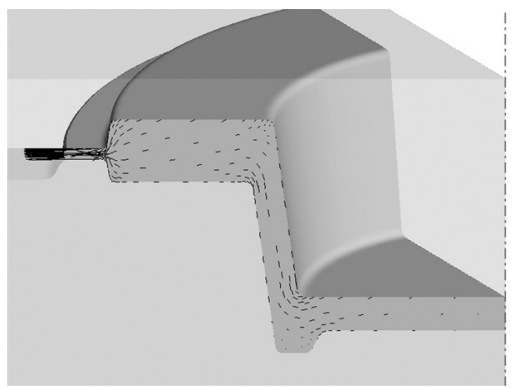

c)

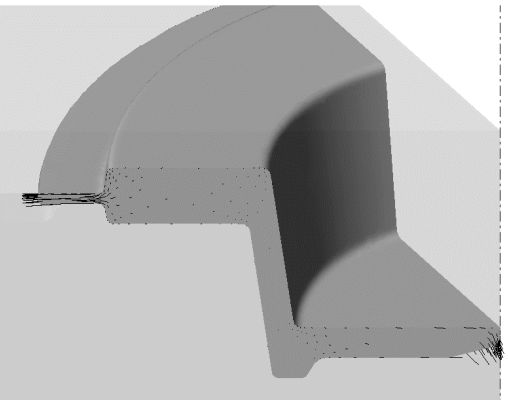

Fig. 5. Vectors of the metal displacement: a) finisher only; b) two-stage forging; c) three-stage forging process 
Proper shape of blocker-die impression enables obtaining thin web in the beginning of the finisher operation, which produces reverse flow direction of inner portion of the performed material (Fig. 5c). Thus, the effect of divided flow is obtained. It should be mentioned, that in the blocker operation there are no peripheral restraints for the deformed metal and the thin web does not call for significantly higher load.

\subsection{Tool stress analysis}

State of stress produced in the workpiece in the finisher impression resulting in high level of mean stresses in the area of the web aroused undesirable excessive level of compressive stresses in a die, resulting in high unit pressure of $1780 \mathrm{MPa}$ in the contact surface (Fig. 6a). The mean stress values exceeded $1150 \mathrm{MPa}$ in the web area, changing into tensile stresses reaching $700 \mathrm{MPa}$ in the fillet of the tool (Fig. 7a). Equivalent stress thus got

a)

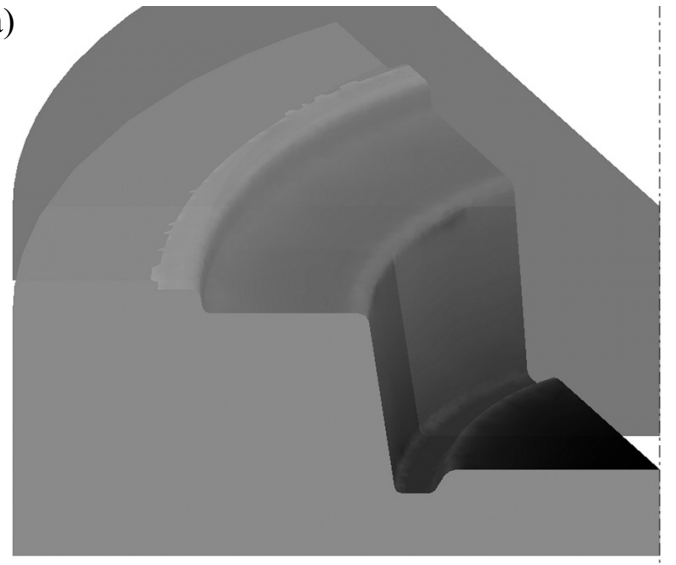

Contact pressure

b)

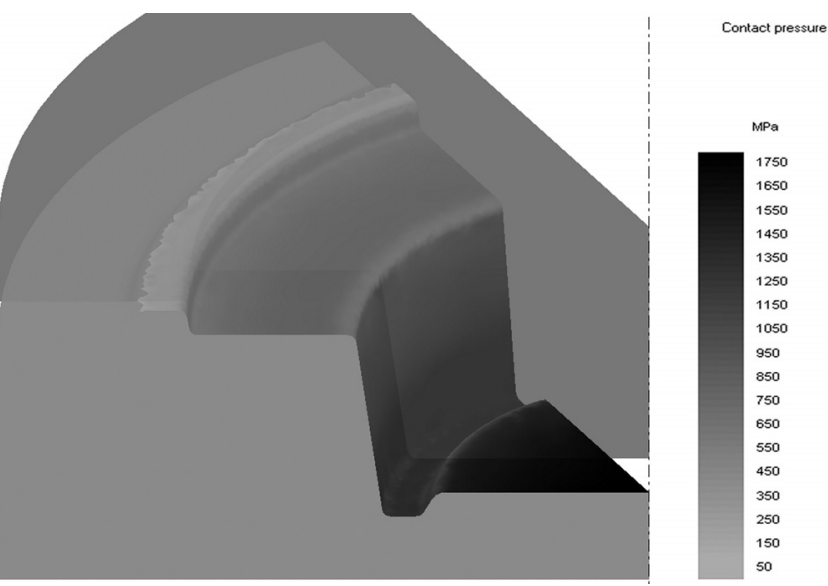

Fig. 6. Unit pressure in the bottom metalltool contact surface for the process using: a) upset-forged billet; b) blocker 
particularly high values in two-stage forging process, reaching $1450 \mathrm{MPa}$ in the corner (Fig. 8a). Similar in values were the stresses observed during forging upset-forged ingot. In both ca-ses, in addition to the web area, attention should be paid to high stresses localized in the region of the bottom outer edge of the die, which can lead to the tool damage.

In addition to obtaining sound forging with thinner web by means of division of the metal flow pattern and reduction of dead zone, possibility of the tools loading reduction was investigated. Introduction of thin web reduced the indicators of the loading, particularly their local values in the vicinity of stress concentrators. With a slightly reduced equivalent stress (Fig. 8b) much more reduction in contact-surface pressure (Fig. 6b) and mean stress (Fig. 7b) can be distinguished. Although absolute peak values of mean stress in the corner of a die is a bit higher, it occurs only in several spots and can be attributed to local overestimation of the method, contrary to that in two-stage process, stretching all along the fillet.

a)
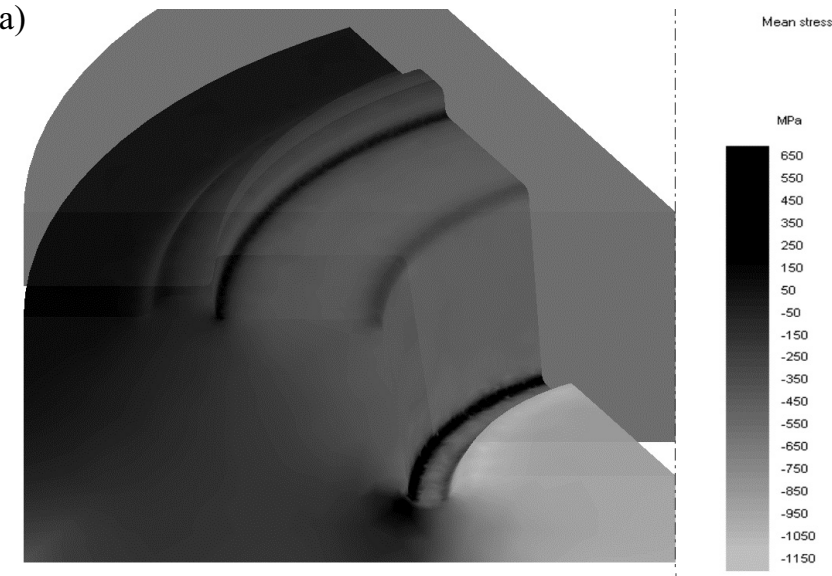

b)
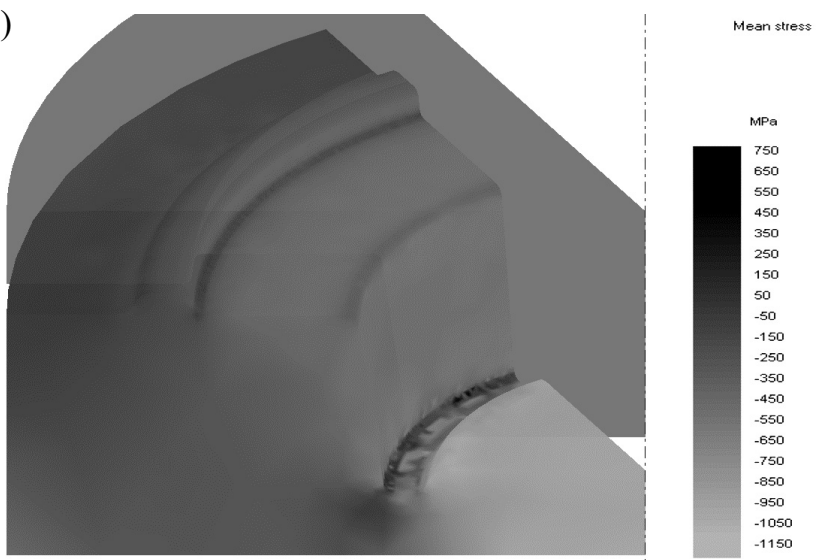

Fig. 7. Mean stress distribution in the bottom tool for the process using: a) upset-forged billet; b) blocker 
a)

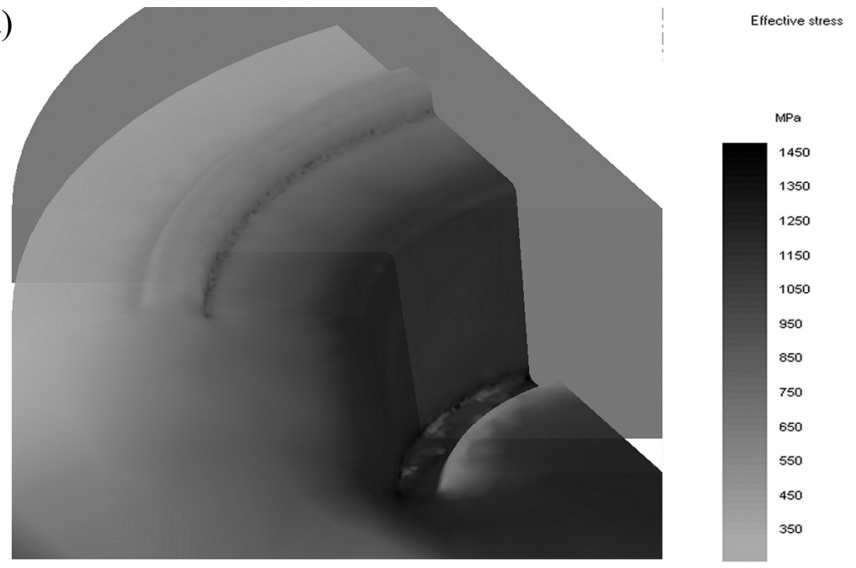

b)

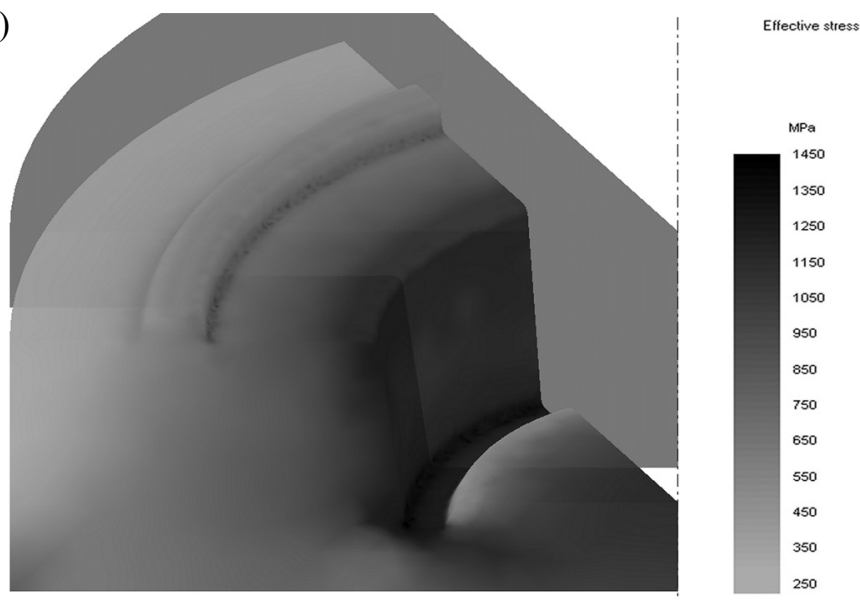

Fig. 8. Effective stress distribution in the bottom tool for the process using: a) upset-forged billet; b) blocker

\section{DISCUSSION}

The results of the studies show advantages of the proposed solution, involving additional blocking impression over conventional upsetting-finish only technology. Both, physical and numerical modelling of the forging process, with satisfactory agreement, indicate metal flow defects occurring during forging in one-, or two-stage process. Flow lines pattern obtained in result of physical modelling of one-stage forging from cylindrical billet (Fig. 2), stopped due to overloading at mere $70 \%$ of high reduction exhibit the tendency of forming a lap. Displacement of the material in the transition area from the wall of the part to outer flange, caused excessive tensile stresses occurrence, proven by numerical analysis. High stresses in the web did not allow for completing the operation on low-capacity laboratory rig. 
These notices are further confirmed by numerical modelling of tool stress. High mean stress values in the area of the corner fillet, which in practice causes severe damages of tools, have been reduced. Although, the difference is not huge, the presented effort does not exploit the possibilities of the solution. The key issue is here to provide division of the metal flow in thin sections of the formed part and attain it until the last stage of the impression fill out.

Introduction of a blocker die provided smooth profile of flow lines, and furthermore, allow thinner web to be obtained, due to lower stresses in the web. Thinner web and lack of defects result from favourable metal displacement in the impression preceding the finisher. Although the concept of the inward metal flow in the forging operation is known, it has usually involved additional gutter in the web. Since no change or additional allowance is designed, the divided flow pattern is forced by proper metal displacement in a blocker impression.

\section{CONCLUSIONS}

Physical and numerical modelling of a forging process of a flange was carried out. Three different solutions of forging technology have been taken into consideration. In order to provide more favourable metal flow kinematics in the last stage of forging in finisher die, modification in design of blocker die was made. The blocker produced divided flow pattern in the finisher die, resulting in elimination of metal flow defects and reduction of loading and stresses in tools.

Metal flow FEM analysis, based on profiles of under-surface lines and metal flow velocity vectors allowed finding appropriate displacement in a blocker die, which produced pattern of divided flow in the finisher. Elimination of dead zone in the axis and corner of the impression cavities brought about inward flow direction, reducing period of action of excessive stresses on tools. Reduction of mean stress level, effective stress and contact-surface unit pressure indicate increased tool life.

Financial assistance of MNiSzW in the framework of 11.11.110.859

\section{REFERENCES}

[1] Zherebtsov S.N., Fat'yanov S.V.: Centrifugal electroslag casting of annular flange blanks. Chemical and Petroleum Engineering, 41 (2005) 5-6, 348 $\div 350$

[2] Stepanov G.A.: Making blanks of butt-welded flanges from austenic steels. Chemical and Petroleum Engi-

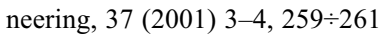

[3] Sińczak J., Kusiak J., Madej W.: Analiza płynięcia metalu w procesie kucia wielowykrojowego odkuwek osiowo-symetrycznych. Obróbka plastyczna metali, 5 (1994) $1,11 \div 15$

[4] Sińczak J., Skubisz P.: Modelling of the forging process of a complex-shape part. Proceedings - International Scientific Conference on the occasion of the $55^{\text {th }}$ anniversary of founding the Faculty of Mechanical Engineering, VSB - Technical University of Ostrava, September 7-9, 2005, p. 31 
[5] Choi J.C., Choi. Y.: Precision forging of spur gears with inside relief. International Journal of Machine Tools \& Manufacture, 39 (1999), 1575 $\div 1588$

[6] Kazanecki J.: Wytwarzanie rur bez szwu. Wydawnictwo AGH, Kraków 2003

[7] Brózda J., Zeman M.: Wrong heat treatment of martensitic steel welded tubes of resuperheaters in a fossil fuel power plant. Engineering Failure Analysis, 10 (2003), 569 $\div 579$

Received

November 2008 